\title{
A values-based analysis of bifurcation bias and its impact on family firm internationalization
}

\author{
Alain Verbeke ${ }^{1,2,3} \cdot$ Wenlong Yuan ${ }^{4} \cdot$ Liena Kano $^{1}$
}

Published online: 8 June 2018

(C) The Author(s) 2019

\begin{abstract}
Recent analysis of family firm internationalization has shown that international performance can suffer when family owners or managers engage in an unwarranted, strict separation between two 'generic categories' of resources in their strategic decisionmaking. On the one hand, there are resources perceived as 'being part of the family in the long run', and therefore unique and worthy of nurturing. On the other hand, there are resources perceived as 'with the family only for the short run', and therefore having commodity-type status and being fungible. The concept of bifurcation bias describes this frequently observed, affect-based phenomenon of separating all resources utilized by the firm into two categories. Bifurcation bias has been argued to be particularly damaging in the context of internationalization, whereby accurate assessment and complex recombination of resources is critical. In this paper, we extend the analysis of bifurcation bias in family firms. We examine how the personal values of family firm owners and non-family members, as well as the dominant cultural values in the relevant, surrounding societies (both home and host), can influence the magnitude and dysfunctional effects of this
\end{abstract}

Alain Verbeke, Wenlong Yuan and Liena Kano contributed equally to this work.

Alain Verbeke

averbeke@ucalgary.ca

Wenlong Yuan

wenlong.yuan@umanitoba.ca

Liena Kano

liena.kano@haskayne.ucalgary.ca

1 Haskayne School of Business, University of Calgary, 2500 University Dr. NW, Calgary, AB T2N $1 \mathrm{~N} 4$, Canada

2 Henley Business School, University of Reading, Reading, UK

3 Solvay Business School, Vrije Universiteit Brussel (VUB), Ixelles, Belgium

4 Asper School of Business, University of Manitoba, 181 Freedman Crescent, Winnipeg, MB R3T $5 \mathrm{~V} 4$, Canada 
phenomenon. Infusing values-based analysis into assessing how bifurcation bias plays out in family firms, can improve our understanding of family firm heterogeneity, has implications for empirical research, and may help invalidate some overgeneralized narratives in research on family-firm international behaviour.

Keywords Bifurcation bias · Family firms - Internationalization · Human values · Societal values

Extant research on strategic decision making in family firms has often attempted to make generalizable distinctions between these companies and non-family ones. For example, in the realm of internationalization, past research has focused on whether family firms are more or less internationalized than non-family firms (Banalieva \& Eddleston, 2011). In trying to answer this question, scholars have identified specific features of family firm governance that might either promote internationalization or act as a deterrent to internationalization (Claver, Rienda, \& Quer, 2009; Gomez-Mejia, Makri, \& Larraza-Kintana, 2010; Nordqvist, 2005; Miller, Le Breton-Miller, \& Scholnick, 2008).

However, empirical research has produced ambiguous results, ranging from positive to negative and to non-linear relationships between family ownership and internationalization (Sciasca, Mazzola, Astrachan, \& Pieper, 2013). A recent meta-analysis by Arregle et al.'s (2017: 823) even suggests that 'the association between a firm's ownership (i.e. family vs. non-family) and internationalization is null.' Studies have also proposed that the absence of unambiguous results is likely attributable to the failure to account for the impact of firm heterogeneity in diverse external environments, and for firm-specific features, such as idiosyncratic resource bundles (De Massis, Di Minin, \& Frattini, 2015) and the quality of strategy execution (Majocchi \& Strange, 2012).

Most recently, scholars have proposed that bifurcation bias, i.e., an affect-based distinction made by family owners (and managers) between family-based resources (high uniqueness status) and non-family resources (commodity status), can help explain the diverging internationalization levels of family firms vis-à-vis other types of companies (Kano \& Verbeke, 2018; Majocchi, D’Angelo, Forlani, \& Buck, 2018; Verbeke \& Kano, 2012). The observed levels of bifurcation bias, as well as the associated economic activities and performance outcomes can, however, vary across family firms, and lead to significant (but predictable) family firm heterogeneity. Here, Kano and Verbeke (2018) have argued that bifurcation bias may be a distinct feature of family firms as compared to other types of companies, yet it can still vary in family firms, depending, inter alia, on institutional and cultural contexts.

In this study, we extend the analysis of bifurcation bias in family firms by examining how both the personal values of family firm owners versus non-family employees, as well as the broader cultural values in the surrounding societies, can influence the manifestation and impacts of bifurcation bias. Here, we assume that it is the personal values of the 'dominant' family owners/managers that affect family firm functioning, though the personal values of individual family members need not be identical. We explore how these values can influence family firm internationalization from a bifurcation bias perspective. This values-based analysis of bifurcation bias contradicts some common narratives propagated in extant research on family firms and their internationalization behaviour. 
Specifically, much research on family firm internationalization is conducted from a socioemotional wealth (SEW) (Gomez-Mejia, Haynes, Nunez-Nickel, Jacobson, \& MoyanoFuentes, 2007) perspective. It has been argued that family firms' desire to preserve SEW affects their internationalization patterns, in that these firms are likely to choose internationalization paths and strategies that are the least likely to lead to SEW dissipation (Gomez-Mejia et al., 2010). We argue that a focus on maintaining SEW can itself be an expression of bifurcation bias, depending on whether the family's SEW preferences are in line with the long-term economic goals of the business. We link the concept of SEW to personal and societal values, to demonstrate when SEW is more likely to lead to dysfunctional internationalization paths in family firms.

Our study contributes to a better understanding of family firm internationalization in a number of ways. First, we respond to the family business scholars' call for exploring the impact of family firm heterogeneity on international strategy (Arregle et al., 2017). We analyze how various personal (and by extension family) and societal values influence, through bifurcation bias, family firms' propensity to internationalize, as well as the quality of their international governance choices. Second, we make the first steps toward unpacking the notion of bifurcation bias, by analyzing its values-based antecedents.

Prior research has suggested that family firms differ in the extent to which bifurcation bias is present in their governance systems (Verbeke \& Kano, 2012), yet, to the best of our knowledge, the reasons for this variance have not yet been uncovered. Our study suggests that values held by the founding family and by non-family employees, as well as dominant values of surrounding societies, explain both the variance in family firms' propensity to bifurcation bias and the extent of its damaging effect on these firms' performance, successful internationalization and longevity.

\section{Core concepts: Bifurcation bias, human values, societal values}

\section{Bifurcation bias}

Bifurcation bias refers to two systemic, opposed patterns of behaviour directed toward both human and non-human resources, including relational assets (Verbeke \& Kano, 2012; Kano \& Verbeke, 2018). Family-based resources are those closely linked to the family firm owners' (and by extension the family member employees') identity, and they function as an integral part of the family firm's historical trajectory and the way the family perceives the firm's role in the world. These resources can include human assets, physical and non-physical assets, but also higher-order resource combinations and relational assets. All other resources, i.e. those that are not explicitly linked to the family's history and identity, represent non-family resources.

Bifurcation bias arises when managerial practices are systematically geared toward treating the family-based resources as unique, valuable, and non-fungible, and nonfamily ones as commodity-like and fully fungible. For example, in the case of human resources, bifurcation bias occurs when family members are automatically assumed to be loyal and fully committed to serving the ultimate goals of the firm, whereas nonfamily members are treated by default as disloyal and self-serving.

The extant literature on family firms has documented some typical forms of bifurcation bias, such as family members' reluctance to monitor and discipline each 
other, and the simultaneous, indiscriminate lack of 'trust' of outsiders (Dyer, 2006). SEW, as discussed above, can also be a manifestation of bifurcation bias, in cases where the founding family seeks to promote socio-emotional preferences that "[feed] parochial family desires" (Miller, Wright, Breton-Miller, \& Scholes, 2015: 21) namely, family-centric preferences that cater to personal interests and emotions of the family at the expense of the long-term health of the business. In managerial practice, bifurcation bias can manifest itself in many aspects of a family firm's operations, such as recruitment, promotion, performance evaluation, compensation, and resource allocation. For instance, appointing an outsider to an important position only temporarily, until a member of the family offspring can qualify to take his or her place (typically when a formal, age-related threshold or minimum educational requirement is met) reflects the highly differentiated selection criteria applied to family versus non-family members (Lee, Lim, \& Lim, 2003).

Bifurcation bias can lead to several forms of inefficiency, because the uniqueness and potential contributions to profitability and growth of family-based resources versus non-family ones are typically wrongly assessed. Examples include overestimating the actual contributions made by weakly motivated family members who may occupy key positions in the firm, and underestimating the contributions of highly motivated, nonfamily members, who are wrongly viewed as intrinsically unreliable. The issue of bifurcation bias can be particularly problematic in the context of international expansion, where it is critical to evaluate correctly the non-location-boundedness (absence of limits on the international transferability, deployability and profitable exploitation) of the family firm's reservoir of resources, and the need to combine the firm's extant resource base with new resources (Zahra, 2003; Carney \& Gedajlovic, 2003).

Internationalization requires family firms to transfer existing firm specific advantages (FSAs), i.e. idiosyncratic resource bundles that have served the firm well at home, and to recombine these FSAs with host country resources (including those provided by new partners) in foreign locations (Verbeke, 2013). Bifurcation bias can then inhibit the efficient international deployment of resources, and hinder requisite resource recombination processes, namely when family decision-makers overestimate the non-location boundedness of family-based resources and underestimate the economic potential of non-family resources. For example, they may try to deploy abroad location-bound, family-based resources, in situations where these resources have little profitable exploitation potential in foreign markets, and they may also be reluctant to recombine these resources with locally accessed, non-family resources, that would permit national responsiveness. Kano and Verbeke (2018) have discussed the negative impacts of bifurcation bias on key international governance decisions, such as the choice of host country locations and operating modes. Specifically, personal preferences of family members may take precedence over efficiency-based evaluation of host location advantages. Affect-based selection of operating modes, particularly in the realm of (de-)internalization, may not align with efficiency-based, optimal choices; timing of (de-) internalization may also be suboptimal. The buildup of these potentially dysfunctional, theoretically misaligned governance choices creates family firm-specific barriers to successful internationalization.

Bifurcation bias is a relatively new construct, with little empirical research presently available to illustrate it. However, some noteworthy strides have been made into testing the impact of bifurcation bias on family firm internationalization. 
In a recent study, D'Angelo, Majocchi, and Buck (2016) demonstrate that such safeguards against bifurcation bias as employing professional managers and opening governance structure to external influences, are positively associated with international scope of family-owned SMEs. In a follow-up study, Majocchi et al. (2018) empirically showed that purposeful safeguards against bifurcation bias increase family owned SMEs' export intensity.

Verbeke and Kano (2012) define bifurcation bias as an important feature of family firms, but they also do acknowledge that not all family firms suffer equally from this bias, with most firms finding themselves at some point on a continuum from severely biased to completely unbiased. Further, biased and unbiased practices may coexist in an organization, in relation to different resource bundles and routines, and/or at different organizational levels. Jennings, Dempsey, and James (2018) developed a typology of bifurcated human resource practice bundles in family firms and identified six different types of bifurcation, based on both the extent and specific targets of bifurcation practiced by the dominant family.

Importantly, not all biased firms are to the same extent negatively affected in terms of performance outcomes. ${ }^{1}$ The damaging effect of bifurcation bias can be moderated by organizational structure, technological complexity, the firm's cultural and institutional environment, etc. Specifically, Verbeke and Kano (2012) note that in relational contracting cultures where both family and non-family members are expected to be loyal (e.g., Asian cultures such as Japan), bifurcation may be less damaging, whereas in formal contracting cultures such as North American and European countries, where loyalty does not play the same role as in relational contracting cultures, non-family members may respond to family firm owners' particularistic treatment of family members with unreliability, including shirking and free riding. Here, national relational cultures can act as an informal, macro-level safeguarding tool to correct for the negative effects of poor micro-level decision-making: Non-family employees remain loyal to the firm and committed to its profitability and growth. Verbeke and Kano (2012) also did mention the potential influence of families' values on bifurcation bias, but extant research has not explored further the nature of the relationship between these two variables.

Since values represent "transituational goals, varying in importance, that serve as guiding principles in the life of a person or a group" (Schwartz \& Rubel, 2005: 1005), dominant family values (Hall, Melin, \& Nordqvist, 2001), such as the family's shared paradigm and beliefs, can affect the manifestation and impacts of bifurcation bias. Here, we assume that family firm owners will exert significant influence when managing the company, in a way that fits with their values (Arregle et al., 2017; Zellweger, Kellermanns, Chrisman, \& Chua, 2012): There is a distinct imprinting of the owning family's values on the family firm's strategic direction and functioning. Values thus act as guiding principles that define how the family firm will make sense of its environment, allocate resources, and make strategic decisions, including internationalization decisions. In addition, differences in societal values, beyond the distinction noted above between formal

\footnotetext{
${ }^{1}$ Jennings et al. (2018) argue that bifurcated practices in family firms are not necessarily dysfunctional. However, our view is that bifurcation bias represents an affect-based decision rule and therefore is likely to interfere with efficient governance, at least in the short- to medium term. Purposeful bifurcation, i.e., targeted asymmetrical treatment of family versus non-family resources for (boundedly) rational reasons, is different from bifurcation bias, in that, unlike the affect-based bias, it serves efficiency purposes.
} 
and relational contracting cultures, may also matter. We thus highlight both personal and societal values as important antecedents of bifurcation bias in family firms.

Scholars have proposed various values-based models, but our conceptual model is built upon Schwartz's dual theory of values. At the personal level, Schwartz (1992) addresses basic human values, which reflect individuals' personalities and describe individual idiosyncrasies within any society. At the societal level, Schwartz (1999) considers cultural values and focuses on normative value orientations that differ from one society to the next (Schwartz, 2010). The cultural values orientation of a particular society represents the mean of all individual values in that society, but does not take into account the variations across individual values.

Schwartz's dual theory of values facilitates an analysis that incorporates both personal and societal-level cultural values, yet it is relatively underutilized in international business research, perhaps due to its complexity relative to other values-based frameworks. ${ }^{2}$ International business scholars often adopt frameworks such as Hofstede's (1980), which imply significant within-country consensus ànd crosscountry variability of individual values. However, the assumption of country-level homogeneity is flawed: Fischer and Schwartz (2011) demonstrate empirically that for most values, country differences contribute only modestly to explaining variance, whereas there are only low to moderate levels of within-country consensus. Only a small set of values exhibit both high within-country consensus ànd cross-country differences. This empirical evidence supports the sociological perspective on values (e.g., Hitlin \& Piliavin, 2004), which implicitly assumes only moderate within-country consensus by treating values as reflections of power struggles, and value conflict as a major driver of social movements. Or to phrase this differently: Although individuals may be embedded in the same macro-level context, they will internalize macro-level values on the basis of their specific interests and idiosyncratic experiences.

In addition, the same value can take on a different meaning and have different normative implications, depending upon whether it is considered at the individual versus the societal level. Schwartz gives the following example when making a case for the need to separate personal and societal values: 'Humility' as a personal value encourages people to be submissive, but 'humility' as a cultural value in a society calls for the usage of hierarchy to regulate social interactions, and in such case "effective hierarchies require people to exercise authority over those below them but also to show humility toward those above them" (Schwartz, 2010: 478). As such, simultaneous consideration of personal and cultural values is likely to yield more accurate predictions, particularly in contexts where individual values interact with societal values.

Internationalization represents a context whereby both micro-level variables (i.e., basic human values of individuals who make internationalization decisions) and macro-level

\footnotetext{
${ }^{2}$ The separation between personal values and cultural (societal) values in Schwartz's research can cause confusion. As Schwartz himself notes: "Until recently, I avoided discussing my individual-level and culturelevel theories in the same forum. I also refrained from writing about them in the same publication. That was my attempt to prevent confusion. Most writing about the culture level in psychology today, however, whether drawing on my approach or on Hofstede, Triandis, Inglehart, or GLOBE, appears to confuse levels" (Schwartz, 2011: 309). At the societal level, Schwartz conceptualizes cultural values as "the normative value emphases that underlie societal functioning" (Schwartz, 2011: 314). Here, cultural values represent the system of basic societal norms. In contrast to other cultural value theories (e.g., Hofstede, 1980), which view cultural values as the values shared by all societal members, Schwartz does not make such a strong assumption.
} 
variables (i.e., cultural values of home and host societies) affect firm-level outcomes, and therefore, Schwartz's dual theory of values is a particularly suitable model for our analysis. Moreover, Schwartz's dual theory of values is comprehensive, conceptually sound, and captures a full range of value dimensions. The personal values supposedly "are inclusive and leave out no major, distinct values that are meaningful across societies" (Schwartz \& Rubel, 2005: 1010). Likewise, Schwartz's (2006) cultural values at the societal level represent a relatively comprehensive set of cultural value dimensions.

However, Beugelsdijk, Ambos, and Nell (2018) argue that cultural value constructs should always be used as a function of the specific outcome variable studied in international business research, and the dimensions underlying an overall model or index should not be used indiscriminately, divorced from the specific managerial challenge that is being investigated. In the context of our study of bifurcation bias in family firms and their internationalization, this explains why we will focus on specific dimensions of Schwartz's dual theory of values. In the next sections, we first discuss Schwartz's theory of basic human values, followed by his perspective on cultural values at the societal level.

\section{Basic human (personal) values}

Basic human values determine the motivational goals and the desirability of alternative actions (Schwartz, 1992). For family firms, goals determine these firms' willingness to engage in particular courses of action, and they also reflect the desires/demands of their most salient stakeholder groups (Williams, Pieper, Kellermanns, \& Astrachan, 2018). Many family-firm specific goals have been identified in extant research, e.g., relationship-related goals (e.g., keeping family members unified) and SEW-related goals (e.g., maintaining family control), some of these with important implications for management-related outcomes (e.g., family-centered non-financial performance) and strategy-related ones (e.g., internationalization levels).

Schwartz's (1992) theory specifies ten basic values, which can be represented in a twodimensional, circular structure, with four higher-order values. Figure 1 presents an adaptation of the Schwartz theory of personal values, along the lines that we think are most relevant to explaining the occurrence and impact of bifurcation bias in family firms.

The first dimension of the Schwartz theory with two higher-order values - openness to change versus conservation values - contrasts values emphasizing independent thought, favouring change, and readiness for new ideas and actions (i.e., basic values of self-direction and stimulation) with those focused on resistance to change, preservation of traditional practices, stability, and order (i.e., basic values of security, conformity, and tradition). As we will show, this first dimension is particularly important in the context of bifurcation bias in family firms.

The second dimension, with the two other higher-order values, namely selftranscendence versus self-enhancement, contrasts values emphasizing concern with the welfare of others and those focused on the pursuit of power and achievement. We will argue that it is the two basic values within the self-transcendence dimension, namely benevolence versus universalism, which are the most critical to make predictions related to the occurrence and impacts of bifurcation bias. As we will discuss in the last section of the paper, self-enhancement - albeit an often-observed phenomenon in family firms - does not act as a trigger of bifurcation bias, in contrast to common beliefs on the matter. 


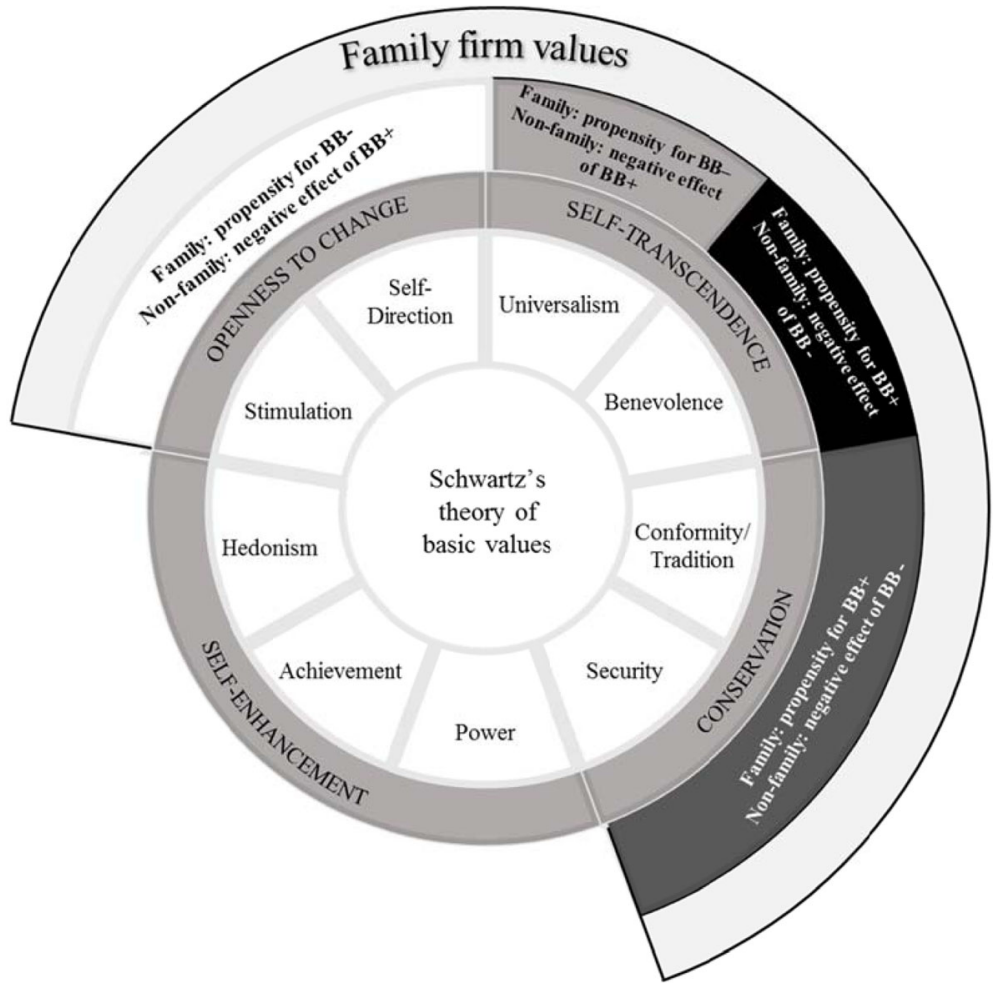

Fig. 1 Bifurcation Bias in Family Firms: A Perspective based on the Schwartz Theory of Basic Values

A major feature of the Schwartz theory of basic values is that these are organized in a circular representation, with more adjacent values bearing more similarity to each other, and more distant values exhibiting a stronger negative association in the value structure. Past studies have examined how these basic values relate to various attitudes, opinions and behaviours (Schwartz, 1996; Schwartz \& Bardi, 2001; Schwartz et al., 2012; Feather, 1988).

\section{Societal values}

Firms are nested within societies, and the surrounding societal values will affect the extent to which practices within family firms are viewed as desirable. For example, family firms in Italy and the US pursue different goals, thereby reflecting the heterogeneous environments in the two countries (Williams et al., 2018). Societal values serve to justify actions that members of this society engage in. Family owners enact their own firm-level cultures over time, while addressing both external and internal challenges (Steier, 2009). Externally (at the macro-level), they must respond to a variety of demands, when accessing requisite resources, producing needed goods, and gaining legitimacy. Internally (at the firm level), they must socialize organizational members and manage integration among different units and functions. In order to achieve environmental fit, family firm owners must gain some threshold level of approval from the society (or societies) in which they operate. The personal values of 
family firm owners and their firms should therefore exhibit at least some alignment with the dominant societal norms. In the absence thereof, family firms may be subjected to pressures and sanctions (e.g., public criticism, ostracism, withdrawal of support) from the relevant society.

Schwartz's (2006) theory of cultural value orientations specifies three dimensions of culture that represent three critical issues confronting all societies: (1) the nature of the relationship between the person and the group; (2) a system to ensure that people behave in a manner that preserves the societal fabric; and (3) the nature of the relationship between people and their social and natural world. Alternative resolutions to these issues represent seven cultural values at the societal level: (1) embeddedness versus (2) intellectual autonomy and (3) affective autonomy; (4) egalitarianism versus (5) hierarchy; and (6) mastery versus (7) harmony. Here, each value relates to a basic dimension in regulating human activity.

Similar to the theory of basic human values, Schwartz's cultural values are arranged in a circular structure, whereby compatible cultural orientations are adjacent to each other, while incompatible ones are distant around the circle. This integrated "nonorthogonal" (Schwartz, 2006: 142) view of cultural values is a core feature that differentiates Schwartz's model from other conceptualizations of culture.

\section{Values in family firms}

In the family business literature, researchers have proposed family values as a major feature of entrepreneurial family systems (Aldrich \& Cliff, 2003), and they have examined the connection between family ties and national economic development (Bertrand \& Schoar, 2006). However, a detailed investigation of how various dimensions of family values shape family firm behaviours, especially in terms of internationalization, is still lacking (Yuan \& Wu, 2018). We attempt to fill this gap in the present paper, by linking values to bifurcation bias and, subsequently, to family firm internationalization. This focus on values extends and provides context to Kano and Verbeke's (2018) earlier assessment of the role of bifurcation bias in internationalization patterns (and the outcomes thereof) in family firms.

\section{Values as determinants of bifurcation bias levels and impacts}

Kano and Verbeke (2018: 11) observed that "not all family firms are bifurcation biased", but they did not investigate the initial root causes of such heterogeneity. In this paper, we argue that family values, and the way these are translated into managerial practices, will affect the scope and level of bifurcation bias in systematic and predictable ways. Kano and Verbeke made three relevant observations in this realm. First, they did argue that bifurcation bias in family firms may be contingent upon the owner-managers' (and their early successors') personalities, belief systems and leadership styles. Second, they suggested that bifurcation bias, particularly in relation to human resources, in turn generates dysfunctional behaviours of family members and non-family members alike. For example, extensive altruism towards family members (Chua, Chrisman, \& Bergiel, 2009) that interferes with objective performance evaluation, can lead non-family members to withdraw effort and 
commitment, as they perceive unfairness in recruitment, performance evaluation, and compensation between family and non-family members. Therefore, personal characteristics of non-family members will influence their reactions (e.g. shirking and other anti-family behaviours) to bifurcation bias, and thereby the latter's compounded, dysfunctional effects on economic performance. Third, as mentioned earlier, Kano and Verbeke recognized that cultural and institutional characteristics, and therefore especially dominant values in the home country, might affect the manifestation and impacts of bifurcation bias.

In the remainder of this paper, we examine the root causes and impacts of bifurcation bias, by studying the personal values of the family firm owners and non-family employees, as well as the values prevailing in various societal contexts. Although all members of the organization could in principle influence the values and managerial practices in family firms, the dominant owner-families may have greater influence because of their intrinsically close connection to the founders, their longterm involvement in the business, and their status (Kelly, Athanassiou, \& Crittenden, 2000; Zahra, Hayton, Neubaum, Dibrell, \& Craig, 2008). Non-family employee values can, however, moderate the dysfunctional effects of bifurcation bias instigated by the family owners' values. As noted above, we use Schwartz's (1992) theory of basic values to develop our propositions regarding how values of family firm owners and non-family employees can influence the occurrence of bifurcation bias and its effects (see Fig. 1).

\section{Personal values of family firm owners}

Family-firm owners' values that strengthen the positive affect in favour of any familybased resource will almost by definition exacerbate bifurcation bias and its dysfunctional effects. Here, we hypothesize that the higher-order dimensions of openness to change versus conservation are particularly relevant to bifurcation bias in family firms. ${ }^{3}$ Conservation values encompass three basic values: security, conformity, and tradition. Security includes both personal security and societal security, with personal security focusing on safety for loved ones and family security. Conformity relates to compliance with rules, laws, obligations, and respect for parents. Tradition emphasizes the preservation of family, and the importance of cultural and religious traditions.

The higher-order dimension of conservation thus typically relates to many familyrelated elements such as obedience to parents and prioritizing family. Irrespective of the location of the family firm's home base, this dimension is particularly salient in families espousing a Confucian philosophy (Luo, 2008), which underscores filial piety, loyalty, and family obligations (Fan, 2000). Families with strong conservation values - as compared to families with openness to change values - will find it perfectly natural and even legitimate to place family members and everything family-related, ahead of nonfamily members in their decisions. They will exhibit asymmetric altruism, nepotism, and other behaviors leading to agency challenges in the operation of their firms. The tendency to provide secure employment and other privileges to family members (Kets

\footnotetext{
${ }^{3}$ We focus on conservation values in the propositions. Conservation and openness to change are the two opposite sides of one single, higher-order dimension. Any predicted, negative effect of conservation could be restated as a predicted, positive effect of openness to change.
} 
de Vries, 1996) reflects the dominance of conservation values and thereby a higher propensity towards bifurcation bias. In contrast, family firm owners with strong openness to change values may be more open to new ideas and exhibit willingness to regulate the influence of family interests. ${ }^{4}$

\section{Proposition 1. Family firm owners holding strong 'conservation' values will be more prone to bifurcation bias, as compared to families with strong 'openness to change' values.}

Strong conservation values of family firm owners may lead to severe bifurcation bias, but other values of these families may exacerbate or weaken this effect. As noted above, the basic values are organized in a circumplex form, with the above two, higherorder values positioned opposite to each other. Here, we will argue that families with different combinations of scores on the openness to change versus conservation dimension discussed above, and on the universalism versus benevolence basic values, within the self-transcendence dimension, may exhibit different behaviours.

The self-transcendence dimension is indeed particularly relevant to our analysis, since it includes the basic values of universalism and benevolence, with universalism emphasizing tolerance and appreciation for the welfare of others, and benevolence stressing preservation and enhancement of the welfare of in-group members. These values can affect the extent to which family firms differentiate between family and non-family members. For example, Jennings et al. (2018) suggest that families with a more open view of the family's boundary may be less likely to view non-family members as outsiders, whereas those with a more closed view may automatically categorize family members as insiders in the long-run and supposedly more committed to the family firm.

In the circular motivational continuum, benevolence is more adjacent to conformity and tradition (i.e., two conservation values), while universalism is more distant from conservation and more adjacent to self-direction (i.e., a basic value of openness to change). As benevolence places emphasis on the welfare of those group members who are in frequent personal contact, family firm owners characterized by a combination of both conservation and benevolence values are likely to show stronger family-centered behaviors and more particularistic treatment of family members (or extended family members). They may thus exhibit stronger bifurcation bias. For example, studies of Chinese family businesses demonstrate that these firms tend to focus on family ties, favor family members in promotion and recruitment, and distrust non-family members as exemplified in their management practices (e.g., Gupta \& Levenburg, 2010; Tan \& Fock, 2001). It has been argued that the distrust of non-family members is stronger in Chinese family businesses than is the case other groups (Tan \& Fock, 2001). Here, the

\footnotetext{
${ }^{4}$ Culture-level comparisons of family firms demonstrate that in Confucian Asia, which emphasizes group solidarity, social order, family security, and respect for tradition (Sagiv \& Schwartz, 2007), there is minimal regulation of family influence and the core purpose of family firms is to preserve and protect family interests (Gupta \& Levenburg, 2010). In Anglo cultures, which have low scores on conservatism and high scores on the independent pursuit of ideas (Sagiv \& Schwartz, 2007), family firms try not only to regulate the family's influence, but also be transparent about the usage of family influence (Gupta \& Levenburg, 2010). These differences at the societal level provide indirect evidence that families with strong conservation values may exhibit higher levels of bifurcation bias, as compared to families with openness to change values.
} 
combination of stronger conservation and benevolence values may lead to the unbalanced treatment of family versus non-family members. In contrast, universalism focuses on protecting the welfare of all people, so that family firm owners who combine conservation and universalism values are likely to care about the equity and well-being of both family members and non-family members alike, and be more restrained in their particularistic treatment of family members. Such restraint could be interpreted as a form of self-control, which deters family firm owners from engaging in myopic, bifurcation biased behaviour (Thaler \& Shefrin, 1981).

Proposition 2. Family firm owners combining strong conservation and benevolence values will be more prone to bifurcation bias, as compared to families combining strong conservation and universalism values.

\section{Personal values of non-family employees}

Non-family employees' values will determine the reaction to the particularistic treatment of family members in distinct ways. ${ }^{5}$ For example, skilled non-family employees may choose not to join the firm at inception, or to shirk and even leave the firm when they perceive expressions of bifurcation bias such as unchecked nepotism, much in line with agency theory thinking (Lubatkin, Schulze, Ling, \& Dino, 2005). In contrast, other non-family employees may remain loyal to the firm, in line with stewardship thinking, even in the presence of nepotism practiced by family firm owners (Vallejo, 2009). Non-family members can therefore behave in ways similar to those proposed in either agency or stewardship theories. Stewardship theory (Banalieva \& Eddleston, 2011; Davis, Schoorman, \& Donaldson, 1997) suggests that non-family employees may well try to serve family firm objectives, and contribute to maximizing shareholder wealth, whereas agency theory (Jensen \& Meckling, 1976) assumes that non-family members will simply pursue their own self-interest.

The point we make in the present paper, is that non-family members' values will determine which prediction from these two contradictory theories, in terms of bifurcation bias' dysfunctional effects, is most likely to materialize. Non-family employees can typically not be expected to co-determine (and potentially moderate) expressions of bifurcation bias, which result from preferences of the family firm owners. However, in line with our above analysis, we propose that the magnitude of the negative impact of bifurcation bias will vary depending on the values held by non-family employees, whereby in some cases employees may not perceive bifurcation bias as unfair, and therefore may not display unreliable behaviour (shirking, perfunctory contributions, etc.) as a response.

Specifically, non-family members with conservation values, as compared to those with openness to change values, may actually view the particularistic treatment of

\footnotetext{
${ }^{5}$ Non-family members do not necessarily share the same values as family members in the family firm, even if both sets of individuals stem from the same culture. Every individual, and also every family, is exposed to and influenced by- societal culture in his/her own way, so that values of individuals (and by extension families) from the same culture, can vary substantially around the mean scores for the various dimensions of this societal culture (Schwartz, 2011).
} 
family members as an appropriate way to manage the family firm. Values reflect a moral obligation to engage in behaviours that will help preserve social relationships (Schwartz, 1992). Non-family members with conservation values will therefore tend to view favourably many endorsements of traditional family relationships. Research based on the similarity-attraction paradigm (Byrne, 1971) has suggested that similarity in attitudes attracts individuals to one another, enhances the development of professional and personal relationships, and increases the desire to maintain group affiliation. Nonfamily members may thus be 'receptive' to the bifurcation bias of family firm owners because of the similarity in conservation values they share with these family firm owners. Yet, while non-family members with conservation values may find acceptable some level of particularistic treatment of family members, such acceptance will not fully eliminate the negative effects of bifurcation bias, especially when asymmetric treatment of family versus non-family resources is very strong. That is, while pushback from non-family members may not be a factor, dysfunctional governance decisions, e.g., in the realm of resource allocation, market selection, authority delegation etc., may still diminish efficiency and performance in the long run.

In addition, a prediction similar to that formulated in proposition 2 could be made when non-family employees' values on the conservation versus openness to change dimension are combined with benevolence versus universalism values. The specific feature of this latter prediction, is that non-family employees' strong value of benevolence is associated with these employees' (perhaps twisted) assumption that they are part of the in-group constituting the firm, ${ }^{6}$ whereas the in-group is defined much more narrowly by the family owners themselves, an asymmetric situation reminiscent of the noble households of the past, with aristocratic or otherwise powerful masters 'of gentle birth' and paid servants.

The new insight on the role of values in family firms is thus that conservation values, reinforced by benevolence values, will increase the magnitude of bifurcation bias if espoused by family owners. Paradoxically, it is these same values, when espoused by non-family employees, which will moderate the dysfunctional impacts of bifurcation bias. The main reason for the predicted latter effect is that conservation and benevolence values, when put into action by non-family employees, elicit stewardship type behaviour, rather than agency type tit-for-tat unreliability. We can thus formulate propositions 3 and 4 as follows.

Proposition 3. Non-family employees with strong conservation values, as compared to those with openness to change values, will reduce the dysfunctional effects of bifurcation bias in family firms.

Proposition 4. Non-family employees combining strong conservation and benevolence values will further reduce the dysfunctional effects of bifurcation bias in family firms, when compared to cases combining strong conservation and universalism values.

\footnotetext{
${ }^{6}$ The extent to which this assumption is realistic may vary somewhat across societies. For example, the Japanese consider employment relationships as part of in-group, whereas most other Asian societies define the in-group as the (extended) family (Hofstede, 2007). This lends some level of credence to Japanese non-family employees' perceived association with the founding family. We will discuss this, and other, effects of societal values on family and non-family employees' behaviours in the following sections of the paper.
} 


\section{Societal values}

Societal values that place emphasis on the central functions of families and hierarchical relations will increase the social approval of the asymmetric treatment at the heart of bifurcation bias. In order to examine the impact of societal culture, we draw upon the first two cultural dimensions and the corresponding five values at the societal level proposed by Schwartz (2006): (1) embeddedness versus (2) intellectual autonomy and (3) affective autonomy; and (4) egalitarianism versus (5) hierarchy. The remaining two values - (6) mastery versus (7) harmony - relate to the relationship of human beings with the natural and social world, and do not have clear, actionable implications for the specific functioning of family firms vis-à-vis other types of firms in the realm of managing bifurcation bias, and mitigating the effects thereof.

The cultural dimension of autonomy versus embeddedness defines the relationship between the person and the group. Embeddedness-centered cultures emphasize group solidarity, family security, social order, tradition, and obedience: People are embedded in the collectivity. Members of such societies are more likely to view asymmetric treatment of family versus non-family members as relatively congruent with general societal practices. Family members and - more importantly - nonfamily employees and individuals outside of the firm (customers, suppliers, partners, etc.) are more likely to view bifurcation bias as acceptable, and will therefore support related managerial practices, thereby increasing the likelihood of bifurcation bias, yet limiting its negative effects.

The cultural dimension of egalitarianism versus hierarchy addresses the way people interact with each other and manage their interdependencies, with the ultimate societal goal being to induce people to behave responsibly toward each other and to consider the welfare of others. In egalitarian cultures, society members view each other as moral equals and are socialized to engage in cooperation as a way to maintain societal order. Conversely, hierarchical cultures manage interdependencies among members by ascribing well-specified roles and defining chains of authority (Schwartz, 2006). People are expected to comply with their obligations, especially those attached to their roles. In hierarchical societies, family members will typically view bifurcation bias in the context of role assignment, and will therefore take such treatment for granted because of their own social power and authority. In turn, non-family members will be more likely to accept such treatment because they will internalize the surrounding culture, and will be less likely to withhold their effort and commitment, even if (unfairly) treated as short term, commodity-type resources serving the family firm.

Proposition 5. In embeddedness cultures, bifurcation bias in family firms will be more prevalent and stronger, but its dysfunctional effects on performance will be weaker, as compared to autonomy cultures.

Proposition 6. In hierarchical cultures, bifurcation bias in family firms will be more prevalent and stronger, but its dysfunctional effects on performance will be weaker, as compared to egalitarian cultures.

Based on the seven cultural values at the societal level, Schwartz (2006) identifies seven cultural groups, including Confucian influenced, West European, English- 
speaking, Latin American, East European, South Asian, and African and Middle Eastern. ${ }^{7}$ The Confucian-influenced region includes countries/regions such as mainland China, Korea, and Thailand. It has a heavy emphasis on embeddedness and hierarchy. The cultural profile of the region is consistent with many analyses of Confucian culture, which emphasizes the mutual obligations and defined roles in social relationships that all 'well-mannered' individuals need to understand and respect (Chai \& Rhee, 2010; De Bary, Chan, \& Watson, 1960). It focuses on elements such as paternal authority, personal trust and reciprocity within a hierarchical structure (Yang, 2002), with subordinates expected to be obedient and loyal to leaders (Pratt, 1991). Inspired by Confucian philosophy, non-family members are more likely to understand and tolerate particularistic treatment of family members, because their traditional social identity expects them to be deferent to authority (Yan \& Sorenson, 2006). In line with our analysis leading to Propositions 5 and 6, we expect both the prevalence of bifurcation bias in family firms in Confucian influenced countries and regions and -paradoxicallyweakened dysfunctional impacts as compared to geographic zones where the values of autonomy and egalitarianism prevail.

Proposition 7. In Confucian influenced countries and regions (as defined by Schwartz, 2006), bifurcation bias in family firms will be more prevalent, but its dysfunctional effects on performance weaker, as compared to other countries/ regions.

\section{The impact of values on family firm internationalization behaviour}

We have proposed above that the personal values prevailing in family firms, including those espoused by family firm owners and non-family members, and the cultural values prevailing at the societal level, will influence the manifestation and magnitude of bifurcation bias, and perhaps, more importantly, its predicted dysfunctional effects on performance.

In the context of internationalization, and in terms of the role of personal values, we focus on values held by the family firm owners (rather than those of non-family employees), assuming that the former will typically determine international governance choices, both in terms of the magnitude and geographic scope of internationalization, and the resulting specific host country strategies, with (domestic) non-family employees acting more in an implementation role.

For example, if a highly knowledgeable, non-family employee were passed over to run a foreign subsidiary because of bifurcation bias, and instead a less qualified and less motivated family member were to run this operation, dysfunctional effects will undoubtedly result, in comparison to 'what could have been', but the non-family employee's role in the performance outcome of the foreign operation will likely be negligible, unless this employee were still involved in the foreign operation, e.g., as the 'number two', supporting the family member in charge. In this last case, it would be possible to test our propositions 3 and 4.

\footnotetext{
7 "The regions show striking parallels with the zones Huntington (1993) suggested, and those Hofstede (1980) and Inglehart and Baker (2000) found" (Schwartz, 2006: 157), but they differ in terms of underlying cultural constructs, methods of measurement, sample selection, and data-gathering periods.
} 


\section{Personal values of family firm owners}

Building upon our earlier analysis, Table 1 suggests that family firms can be divided into four different types based on configurations of the higher-order personal values held by the dominant family, namely conservation versus openness to change values, and the basic values of universalism versus benevolence.

Propensity toward conservation versus openness to change is perhaps the most intuitively understandable in potentially explaining family firms' internationalization levels, and can be linked to the debate on family ownership's restrictive versus facilitating influence on internationalization (Arregle et al., 2017). On the one hand, conservation values will reduce risk tolerance, with family firm owners seeking expansion paths that carry the lowest risk of SEW dissipation and loss of control (Gomez-Mejia et al., 2010). Here, conservation is likely associated with an intrinsic reluctance to internationalize, and if an internationalization decision were made, it will likely be directed towards comparatively lower commitment modes and lower compoundeddistance countries, even if objective analysis of international growth opportunities would dictate higher commitment modes and location in higher compounded-distance countries. The main reason for this is the relative unwillingness to search beyond the family for resources that would support more ambitious and more economically desirable internationalization targets, i.e., this is a form of bifurcation bias.

On the other hand, the openness to change value involves self-direction and stimulation. Self-direction is associated with creativity, imagination, and autonomy of thought and action, and stimulation concerns the pursuit of novelty, adventure, and excitement. International expansion often increases operational complexity because firms must address unfamiliar market conditions, as well as a new culture and institutions, and barriers to international coordination brought by various distance dimensions (Ghemawat, 2001). Such expansion can add significant uncertainty to a variety of performance outcomes. If

Table 1 Impact of Owning Family's Values Orientation on Family Firm Internationalization

\begin{tabular}{|c|c|c|c|}
\hline & & \multicolumn{2}{|c|}{ Basic values within the self-transcendence dimension } \\
\hline & & Benevolence & Universalism \\
\hline \multirow[t]{2}{*}{$\begin{array}{l}\text { Higher order } \\
\text { personal values }\end{array}$} & Conservation & $\begin{array}{l}1 \\
\text { Internationalization }^{\mathrm{a}} \\
\text { Bifurcation bias }^{\mathrm{b}} \\
\text { Comparatively low level of } \\
\text { internationalization with low } \\
\text { quality of international } \\
\text { governance }\end{array}$ & $\begin{array}{l}3 \text { Internationalization }{ }^{\mathrm{a}} \\
\text { Bifurcation bias } \mathrm{a}, \mathrm{b} \\
\text { Comparatively low level of } \\
\text { internationalization with some } \\
\text { barriers to high quality of } \\
\text { international governance }\end{array}$ \\
\hline & Openness to change & $\begin{array}{l}2 \\
\text { Internationalization }^{\mathrm{b}} \\
\text { Bifurcation bias } \\
\text { Comparatively high level of } \\
\text { internationalization with some } \\
\text { barriers to high quality of } \\
\text { international governance }\end{array}$ & $\begin{array}{l}4 \\
\text { Internationalization }^{\mathrm{b}} \\
\text { Bifurcation bias }^{\mathrm{a}} \\
\text { Comparatively high level of } \\
\text { internationalization with high } \\
\text { quality of international } \\
\text { governance }\end{array}$ \\
\hline
\end{tabular}

\footnotetext{
${ }^{a}$ Denotes a negative effect (reduction of the variable's score)

${ }^{\mathrm{b}}$ Denotes a positive effect (increase of the variable's score)
} 
family firm owners espouse the openness to change values, and are willing to contemplate - where economically justified - usage of non-family-based resources and relationships to serve internationalization goals, higher commitment modes and higher compounded distance locations will likely be selected. Here, bifurcation bias, and its dysfunctional outcomes, may be largely eliminated.

In addition, as discussed above, benevolence can increase further a family firm's propensity toward bifurcation bias, while universalism will have the opposite effect. In the context of bifurcation bias when internationalizing, we can therefore distinguish among four relevant combinations of values for family firms, based on conservation/ openness to change (higher-order value dimensions) and benevolence/universalism (basic values within the self-transcendence dimension), as shown in Table 1.

First combination: Conservation/benevolence As discussed above, conservation values will likely inhibit family firms' engagement in high commitment and broad scope international expansion projects. This reluctance will be amplified further in the presence of benevolence values. Families oriented toward benevolence and focused on caring for the 'welfare of their own', may suffer from serious bifurcation bias: They will be reluctant to enlist non-family members for deployment in foreign operations, even when these employees are undeniably competent and reliable. Thus, both the direct effect of conservation and benevolence on internationalization, and their indirect effect (through bifurcation bias) on the level of international expansion and the quality of international governance will be negative. The negative indirect effect should be assessed from a comparable institutional perspective, i.e., through comparisons with outcomes from decision making whereby fact-based rather than bifurcation-biased decisions would be made.

Proposition 8. Family firm owners combining strong conservation and benevolence values will be more prone to selecting lower levels of internationalization and making lower quality international governance decisions, than families holding other combinations of personal values.

Second combination: Openness to change/benevolence Openness to change facilitates internationalization and discourages bifurcation bias, as discussed above. Yet, benevolence values increase the firm's propensity toward bifurcation bias, thus negatively moderating the economizing effect of openness to change. As such, the combination of openness to change and benevolence values is predicted to have a positive, overall effect on the level of internationalization vis-à-vis the first combination, yet some barriers to the proper governance of internationalization projects are likely.

Proposition 9. Family firm owners with strong openness to change values will be more prone to selecting higher levels of internationalization and making higher quality international governance decisions, than families with strong conservation values. If combined with strong benevolence values, the latter will negatively moderate the impact of openness to change.

Third combination: Conservation/universalism Conservation restricts internationalization and stimulates the occurrence of bifurcation bias. Yet, universalism discourages bifurcation bias. As a result, cases whereby family firm owners espouse a combination of 
conservation and universalism values will be more internationalized and more effectively governed, as compared to the combination of conservation values and benevolence.

Proposition 10. Family firm owners with strong conservation values will be more prone to selecting lower levels of internationalization and making lower quality international governance decisions than families with strong openness to change values. If combined with strong universalism values, the latter values will negatively moderate the impact of conservation.

Fourth combination: Openness to change/universalism The openness to change and universalism values represent the opposite of conservation and benevolence, in that they facilitate internationalization and moderate the occurrence of bifurcation bias. As such, the fourth combination of values will be positively associated both with the level of internationalization and with the quality of decision-making related to international strategy. The expectation is to see internationalization decisions on entry mode and location choices similar to those made by well-functioning, non-family firms.

Proposition 11. Family firm owners combining strong openness to change and universalism values will be more prone to selecting higher levels of internationalization and making higher quality international governance decisions, than families holding other combinations of personal values.

Schwartz's theory of basic values focuses on congruity of adjacent values and antagonism between distant values. The adjacency between conservation and benevolence values, and between openness to change and universalism suggests that these two combinations (i.e., shaded cells 1 and 4 in Table 1) are more likely to be observed, while the other two combinations (i.e., cells 2 and 3 in Table 1) may be less common among family firms, thereby providing a clear agenda for empirical testing of the impact of basic values on family firm internationalization and the governance thereof.

\section{Societal values}

Societal values add a level of complexity to understanding correctly the internationalization process in family firms. Operating internationally involves a transfer of FSAs across borders and recombining these FSAs with local resources. Here, bifurcationbiased family firms will typically overestimate the transferability, deployment and profitable exploitation potential of family-based FSAs, while underestimating the potential of non-family FSAs (Kano \& Verbeke, 2018). In this context, cultural proximity between home and host countries can exacerbate the dysfunctional impact of biased decision-making. Such proximity discourages due diligence in terms of assessing properly the actual difficulties of transferring, deploying and profitably exploiting family-based versus non-family resources. Prior research by Banalieva and Eddleston (2011) demonstrates that family firms managed by family leaders typically restrict their activities to the home region, thereby suggesting that proper due diligence is actually done when contemplating expansion to high distance markets. Bifurcation bias may, paradoxically, be more pronounced when home and host countries are culturally close, as family firm owners view the similarity of cultural values as strong 
grounds for the easy transfer, deployment and exploitation of unaltered, family-based FSAs. They incorrectly assume that cultural similarity vitiates the need for adaptation and novel resource combinations, especially when family-based resources are involved.

Cultural proximity itself can be overestimated, creating an illusion of seamless transferability of routines and practices across borders, and leading family managers to ignore cultural distance between seemingly proximate societies. ${ }^{8}$ Let us consider the Asian societies that -as discussed above-attach importance to hierarchy and embeddedness. These societies could be considered culturally proximate on some dimensions, yet are characterized by "distinct and subtle cultural idiosyncrasies" (Thams, Liu, \& Von Glinow, 2013: 466) that govern business exchanges. The differences in values arise from unique histories, religious traditions, and socio-political structures (Sharma \& Chua, 2013). Further, different paces of industrialization and economic development bring different levels of social and cultural change, which affect societies' inherent values orientation (Chia \& MacKay, 2007). These intra-region differences fundamentally affect the cross-border transferability, deployment and exploitation potential of FSAs.

The emphasis on embeddedness itself varies across Asian countries, whereby some societies value the collective more than others. For example, prior research on national values found that India and Japan place a higher premium on autonomy and a lesser emphasis on collectivism/embeddedness than, e.g., China, Indonesia, South Korea and Pakistan (Hofstede, 2007). Further, the very definition of an in-group within which individuals are embedded, differs across these societies. Most Asian societies view the extended family as their core group, while the Japanese consider their employers as fulfilling the role of an in-group (Hofstede, 2007).

Similarly, Asian societies vary in their preference for -and acceptance of- hierarchy. For example, research shows that Singaporean workplace values are closer to Western preferences for egalitarian governance, democracy and participative leadership, than to hierarchy and tolerance of authoritarian leadership traditionally ascribed to Asian societies (Campbell, Bommer, \& Yeo, 1993). Importantly, Singaporean cultural values center on the group and the family, and families are inherently authority-oriented. Yet, Singapore's history as a British colony, its stable and successful open economy, and an educational system that places emphasis on English language training (Campbell et al., 1993), has prompted a cultural shift whereby traditional values do not necessarily apply in business settings. In practical terms, this means that, e.g., a Korean family firm may not be able to seamlessly transfer particularistic personnel practices into its Singaporean subsidiary.

As another example of cultural values and practices imperfectly transferable across borders, the use of informal governance to conduct business transactions can vary strongly across nations. It is generally accepted in the international business literature that the exchange of favours as a means to facilitate economic activity, while occurring in all cultures, is more prevalent in collectivist societies, where both social and business exchanges are built primarily on the concept of communal sharing (Thams et al., 2013; Thomas, Au, \& Ravlin, 2003), and in emerging economies where favour-trading may

\footnotetext{
${ }^{8}$ Here, we should acknowledge that even societies that share cultural values can differ significantly on a number of other distance dimensions, i.e., economically, geographically and institutionally. For the purpose of our analysis, we isolate the effects of cultural distance, while acknowledging that economic, geographic and institutional differences among countries may have linkages with cultural distance, and lead to a particular level of 'compounded' distance.
} 
compensate for the absence or poor quality of formal institutions (Verbeke \& Kano, 2013) - features characteristic of many Asian societies. Yet, scholars suggest that favour-trading varies across Asian contexts, in terms of the kinds of favours exchanged, the mechanisms of favour-trading, and the perception of their ethical acceptability (Karam et al., 2013; Thams et al., 2013). Karam et al. (2013) investigated perceptions of favour-trading in the business context within eleven Asian societies (China, Hong Kong, India, Indonesia, Malaysia, Pakistan, Singapore, South Korea, Taiwan, Thailand, and Vietnam). They found that attitudes toward favours differ significantly across Asian cultures, and depend on the purpose of favours (image management versus self-serving) and specific societal attributes such as, e.g., secular versus traditional orientation, level of in-group favouritism, level of economic development and corruption, etc. Similarly, Thams et al. (2013) explored favour-trading practices in China, Japan and India, and highlighted a number of important cross-cultural variations in the way that the exchange of favours is viewed and conducted in these societies. Important in the context of the present paper is the fact that family ties play different roles in facilitating favour-trading across Asian societies, that is, they are relatively less important in Japan than in China and India (Thams et al., 2013). Similarly, family-centric favours such as nepotism vary across societies and are comparatively low in, e.g., Singapore and India, and relatively high in Pakistan (Karam et al., 2013).

The point of the above, stylized descriptions of variations in national, societal values is simply that cultural proximity on some societal value dimensions, such as, e.g., hierarchy and embeddedness, does not guarantee seamless transferability, deployment and exploitation of management practices across national borders. Bifurcation-biased decision makers, in particular, may neglect to engage in due diligence to understand how subtle differences in values among nations can affect the value of family-based resources deployed in these host environments.

As such, our (somewhat counter-intuitive) argument is that in a family firm internationalization context, perceived cultural similarities within the region will increase the dysfunctional effects of bifurcation bias, in two ways. First, the degree to which bifurcation-biased, family-centric practices themselves are culturally acceptable varies within the region, as discussed above. Second, perceived cultural similarity can create an illusion of seamless transferability of family-based (heritage) FSAs, including routines/managerial practices across borders. This will obscure the need for local adaptation and novel resource combinations in host countries, ${ }^{9}$ as summarized in the following proposition:

\section{Proposition 12. The dysfunctional effects of bifurcation bias in internationalizing family firms will be greater when expanding to host countries that are more culturally proximate to the home country, as compared to entries into more culturally distant countries.}

\footnotetext{
${ }^{9}$ It is important to emphasize that intra-regional cultural differences do not invalidate the benefits of international strategy centered on geographic regions. On the contrary, prior studies have shown that home region-based multinationals pursuing a regional strategy in Asia have greater success in transferring and exploiting their FSAs within the region than do multinationals headquartered outside of the region (Oh \& Rugman, 2007) - that is, the home-region effect remains strong despite cultural, economic, institutional and geographic distances among countries comprising the region. Our argument is that family firm managers must implement safeguards so as not to let cultural proximity on certain dimensions create an illusion of seamless transferability of family-based practices.
} 


\section{SEW preservation and basic values}

We noted above that personal values held by individuals within family firms, as well as cultural values prevailing in home and host societies, play a role - through bifurcation bias - in shaping family firm internationalization, both in terms of propensity to engage in particular international expansion paths, and the associated quality of governance. Diversity of values in family firms has also been captured in García-Álvarez and López-Sintas (2001), but the Schwartz approach adopted here provides a stronger theoretical foundation for analyzing the impact of family values. Ultimately, this values-based analysis highlights that generic, broad-based comparisons between family and non-family firms, in terms of their internationalization patterns and associated governance, suffers from a grave, omitted variable bias (Bennedsen \& Foss, 2015), that is, a failure to consider the important heterogeneity of family firms themselves (De Massis et al., 2015; De Massis \& Wang, 2018).

The question then arises how our analysis can be linked to the popular SEW concept. Scholars have argued that entrepreneurial behaviours and, more generally, management practices in family firms may be negatively affected by the families' desire to create and protect SEW. Family members may be cognitively biased toward respecting family-espoused values when making important strategic decisions, and, ultimately, may view entrepreneurial activities as a risk to the family's long-run wealth. In the context of family firm internationalization, any instance of international expansion beyond mere replication can be considered as an entrepreneurial act, which entails risk and uncertainty and requires entrepreneurial resource recombination. Strong SEW preferences can therefore interfere with successful internationalization, by leading family firms to pursue paths that carry the least potential for SEW dissipation (Gomez-Mejia et al., 2010). This may entail, inter alia, avoiding international expansion altogether, avoiding risky expansion into high-distance (yet potentially profitable) countries, or choosing potentially less efficient operating modes (e.g., full ownership) specifically because of their perceived capacity to preserve SEW.

Family equity and family control have been argued to constitute key components of SEW (Gomez-Mejia et al., 2007; Gomez-Mejia et al., 2010; Miller et al., 2015; Patel \& Chrisman, 2014). Family equity is the percentage of the business that is owned by family members. Family control refers to owner-managers' strong desire to keep their business-related decision-making in the family across generations. These two oftennoted elements of family culture - desire for family equity and family control - are typically interrelated, in that a higher share of family equity in total equity provides additional voting rights (sometimes amplified by preferred voting rights structures) and, consequently, a higher level of control over resource allocation.

Yet, it is precisely the continued family equity and control that have been linked to a negative impact on entrepreneurial activities of family firms (Berrone, Cruz, \& GomezMejia, 2012), international and otherwise. Herein lies an interesting puzzle coming out of family firm research: How can family firms ensure that decisions and actions conducive to SEW do not simultaneously lead to a reduction of the family's longterm economic wealth, through inhibiting international entry and dampening entrepreneurial activity across generations?

In our view, it is not the focus on maintaining family equity and control per se that reduces entrepreneurial activities and potentially lowers both economic wealth and 
other key components of SEW (such as family identity and the perpetuation of a family dynasty) in all circumstances. In terms of the values-based framework we have proposed, a focus on equity and control largely reflects the higher-order dimension of self-enhancement (and especially the basic value of power), which in turn will strongly influence the extent to which family firm owners will attempt to protect their wealth. Self-enhancement does not in and by itself determine whether a family firm is growth-oriented, as measured by its entrepreneurial activities and the extent of internationalization. Entrepreneurial activity (and, consequently, internationalization) levels are more likely to depend on the conservation/openness to change dimensions, with the latter conducive to more entrepreneurship and greater internationalization.

As specific examples of diverging impacts of SEW, consider contrasting cases of U.S.-based agribusiness conglomerate Cargill and Indian packaged plant business Nurturing Green. The Cargill Macmillan family behind Cargill chose to spin off its profitable fertilizer business rather than taking the company public. While allowing the family to maintain control over the business, i.e., to stay in power, the spin-off ultimately diminished Cargill's ability to compete internationally (particularly with Japanese family-owned competitors that were diversifying control), eroded its profitability and inhibited future growth (Tan \& Wiwattanakantang, 2016). Here, the focus on SEW preservation, proxied by the strong value of power, ${ }^{10}$ was accompanied by conservation, with the latter being the reason for subsequent decline. SEW preferences in this example fall into the category of dysfunctional ("parochial") SEW described by Miller et al. (2015: 21). Conversely, Annu Grover, the founder of Nurturing Green, fought to maintain equity in the business in order to ensure employee satisfaction, pursue innovation, and achieve his vision for leadership in the industry (Pandit \& Sahay, 2013). In this latter case, SEW preferences (again building upon the same value of power) went hand-in-hand with openness to change rather than conservation, and served the long-term economic interests of the family, thereby falling into the functional category ("evergreen") SEW category (Miller et al., 2015: 21).

Likewise, the desire for transgenerational control, as an expression of the importance attached to the 'power' value, can either create or destroy economic wealth, depending upon the presence of conservation versus openness to change. For example, at The Charoen Pokphand Group (CP Group), a Thailand-based agricultural and industrial conglomerate, transgenerational continuity is supported by openness to change evidenced throughout the firm's history, e.g., professionalization, IPO, radical reorganization, a series of divestments, and an emphasis on continued exploration of start-up ideas (Kirby \& Manty, 2011).

On the other hand, primo geniture family firms (i.e., family firms that by default pass management control to the eldest son) tend to be characterized by bad management practices, leading to a long-term decline in profitability (Bloom \& Van Reenen, 2010). Here again, it is not self-enhancement per se that is the problem, but rather conservation values triggering dysfunctional outcomes.

\footnotetext{
${ }^{10}$ In Schwartz's basic human values framework, the basic value of power is one of the components of a higher-order value of self-enhancement. We did not focus on basic values comprising the self-enhancement dimension in this study; however, future research could further explore the impact of these values on family firm strategies, particularly in relation to SEW-related actions and outcomes.
} 
In family firms, at least some focus on SEW - expressing the dimension of selfenhancement - is to be expected. When combined with openness to change, no dysfunctional effects are predicted. Openness to change can imply merit-based selection and promotion of leadership, targeted training programs for family members, structured strategic planning and decision-making processes, rigorous performance benchmarking, and purposeful exposure to unbiased external scrutiny. Family firms that survive through generations, internationalize successfully, and achieve high levels of innovation and performance tend to cultivate bundles of these practices as part of international strategic governance (Verbeke \& Kano, 2012; Kano \& Verbeke, 2018).

\section{Discussion and conclusions}

We have extended the discussion of bifurcation bias in family firms by exploring the potential of adopting a values-based approach. Building upon the well-known Schwartz models of basic human and cultural values, we have described the dimensions of values relevant to expressions of bifurcation bias in family firms. We have discussed how these values can influence the magnitude and dysfunctional effects of bifurcation bias in various societal contexts.

Our contribution to research on family firm internationalization, and, more broadly, family business, is five-fold. First, we contribute to the understanding of family firm heterogeneity, which has recently emerged as a core question in family business studies. We show how differences in values held by families, non-family employees, and surrounding societies affect family firms' actions and outcomes, including their internationalization behavior.

Second, we analyze values-based antecedents of bifurcation bias. While it has been previously acknowledged that the extent of family firms' propensity toward bifurcation bias, its specific expressions, and the magnitude of its impacts vary across family firms, the reasons for the variance have not yet been examined. We suggest that the personal values held by family owners affect family firms' susceptibility to bifurcation bias; the values held by nonfamily employees influence the severity of the bias' damaging consequences; and dominant values of surrounding societies can shape the propensity for bifurcation bias, the severity of its outcomes, and the transferability of resources and practices across national borders.

Third, we discuss specific mechanisms whereby personal and societal values affect family firms' propensity to internationalize and the quality of their international governance. We argue that the presence of bifurcation bias does not necessarily always enhance or constrain the level of internationalization of family firms. However, bifurcation bias does determine whether international governance choices are efficient. Distinct combinations of personal value dimensions, as discussed in this paper, affect internationalization both directly, through encouraging or discouraging entrepreneurial activity, and indirectly through promoting or preventing bifurcation bias.

Fourth, we link our values-based analysis to SEW - a dominant construct in family firm research, frequently used in internationalization studies to explain specific international configurations and choices of family firms. We argue that SEW in and by itself does not explain family firm internationalization, nor does it account for either the functional or dysfunctional outcomes of international strategy. However, linking SEW with bifurcation 
bias allows separating functional SEW preferences from dysfunctional ones. We discuss how dominance of specific personal and societal values can predict whether SEW will be more likely to contribute to, or erode a family firm's long-term health and successful internationalization. We show that the common narrative of SEW effects on internationalization is largely overgeneralized. Rather than leading family firms towards the internationalization paths associated with the lowest risk of SEW dissipation, as assumed in much family firm research, SEW orientation can have a variety of positive or negative impacts, determined inter alia, by the personal values of the actors involved.

Fifth, we contribute to the dual Schwartz theories of values by developing propositions that can be tested empirically in the context of family firms. We have selected a limited set of value items because of their immediate relevance to bifurcation bias and family firm internationalization. Yet, additional questions could be raised. For example, how do other higher-order values, such as self-enhancement, and other basic values, such as power and achievement, matter to family firms? We have touched on the impact of the basic value of power on family firms' desire to preserve SEW (and resulting internationalization strategies), however, future studies can investigate this relationship in more depth. Further, we focused on the high-order value of conservation, but variances in the basic values that form conservation, including security, conformity, and tradition, may impact family firm behavior and its outcomes in nuanced ways. Future research can explore how the remaining basic values or their configurations affect family firm behavior.

At the societal level, we focus on one of seven cultural groups identified by Schwartz (2006), namely the Confucian-influenced region. However, family firms in the remaining regions may be subject to other, specific associations between societal values and firm-level behaviour patterns and outcomes, as manifested by the prevalence and impact of bifurcation bias.

Schwartz's dual theory of values has allowed us to explore the effects of both individual and societal values on family firms' propensity toward bifurcation bias, on the impact of such bifurcation bias, and on family firm internationalization behavior. However, we explored these linkages separately. Future empirical research should include multi-level analyses to understand how individual and cultural values interact to influence family firm behavior.

We formulate twelve propositions, which can be tested in future studies. Recently, worthwhile attempts have been made to operationalize mechanisms reducing bifurcation bias, including measuring safeguarding practices in family firms, estimating openness of governance, using the presence of professional leaders as a proxy for good governance, and measuring training offered to family owners and managers. Future studies could develop additional proxies to measure bifurcation bias, and use existing and new measures to test relationships between personal values, bifurcation bias and internationalization, as proposed by our framework.

Future research could rely on the framework developed here to explore, predict and test specific strategic choices of family-owned multinationals. For example, Kano and Verbeke (2018) argue that the presence or absence of bifurcation bias explains entry mode choices of family firms. Their study could be complemented with this values-based analysis to predict how basic value combinations influence family firm operating modes in host markets. Further, the framework could be used to analyze family-owned multinationals' propensity to engage in network forms of governance. Here, basic values can act as determinants of the family's willingness to engage with family outsiders, release some 
of the control of core processes, and rely on complementary resources of external actors. On the other hand, efficiency of a multinational network with a family firm at its core will depend on the extent to which basic values held by potential network partners in host countries: (1) are consistent with the family's values; and (2) more generally, allow for the promotion of family-centric objectives through the network.

Finally, the values-based framework can be used to predict specific geographic configurations of family-owned multinationals. For example, personal values that inhibit entrepreneurial action and promote bifurcation bias, such as conservation and benevolence, are also likely to slow down inter-regional expansion and strengthen the home region effect (Rugman \& Verbeke, 2004), even though - paradoxically- the effects of bifurcation bias may be the strongest in these proximate countries. As such, family-owned multinationals where family owners hold the above values are likely to be more regionalized, as compared to their counterparts holding openness to change and universalism values. Future research could investigate and test these relationships.

Our study holds practical implications for family firm owners and managers by highlighting instances where the consequences of bifurcation bias are likely to be particularly damaging. Our analysis suggests that values represent one of the determinants of an individual firm's 'initial position' in the realm of bifurcation bias manifestation and dysfunctional impacts. In other words, values influence the firm's ex ante starting point on a continuum from biased to unbiased, as well as the magnitude of the dysfunctional impact on performance outcomes, should the biased position be maintained. Specifically, dysfunctional effects of bifurcation bias are greater in autonomous and egalitarian cultures, and in situations where nonfamily members hold openness to change (as opposed to conservation) personal values. Further, in the context of internationalization, cultural proximity between home and host countries can, paradoxically, exacerbate the dysfunctional impact of bifurcation bias in international strategy by obscuring barriers to transferability of family-based FSAs. It is only through highly disciplined governance and learning from errors, that the occurrence and dysfunctional effects of bifurcation bias will be mitigated. Especially firms owned by families with a high intrinsic propensity for bifurcation bias, and with a high severity of bifurcation bias outcomes, will benefit from ex ante economizing through corrective governance.

It must be reiterated that the impact of bifurcation bias on the performance and survival of family firms is heterogeneous and fine-grained. Particular combinations of personal and societal values, as discussed in the paper, can contribute to -or reduce- the long-term negative effects. But we acknowledge that by selecting the Schwartz models of values, we have limited ourselves to exploring only a few dimensions (albeit critical ones) that can potentially affect the family firm's performance, successful internationalization and longevity. In line with prior work, we should also note that the effects discussed in this paper are likely more valid in fast-paced, complex industry environments, where continued and artful resource re-combinations are critical (Verbeke \& Kano, 2012).

There is a great paradox associated with highly focused attempts to improve family firm performance building upon family-based resources only: Unqualified promotion of family-based resources, driven by the personal values of conservation and benevolence, at the expense of openness to change and universalism, will ultimately fail future family generations in terms of both economic wealth creation and SEW preservation. Here, a focus on family equity and control (driven by the 'power' value) as discussed so often in the prior literature, is neither 'good' nor 'bad' in general terms, as to what it 
might imply for performance metrics. Rather, it is combining conservation and benevolence that would appear to exacerbate bounded reliability challenges and their dysfunctional effects. Awareness of critical combinations of personal values espoused by a family may go a long way to help family firm owners establish proper governance mechanisms that would allow economizing on bifurcation bias.

Open Access This article is distributed under the terms of the Creative Commons Attribution 4.0 International License (http://creativecommons.org/licenses/by/4.0/), which permits unrestricted use, distribution, and reproduction in any medium, provided you give appropriate credit to the original author(s) and the source, provide a link to the Creative Commons license, and indicate if changes were made.

\section{References}

Aldrich, H. E., \& Cliff, J. E. 2003. The pervasive effects of family on entrepreneurship: Toward a family embeddedness perspective. Journal of Business Venturing, 18(5): 573-596.

Arregle, J. L., Duran, P., Hitt, M. A., \& Essen, M. 2017. Why is family firms' internationalization unique? A meta-analysis. Entrepreneurship Theory and Practice, 41(5): 801-831.

Banalieva, E. R., \& Eddleston, K. A. 2011. Home-region focus and performance of family firms: The role of family vs non-family leaders. Journal of International Business Studies, 42(8): 1060-1072.

Banalieva, E. R., Eddleston, K. A., \& Zellweger, T. M. 2015. When do family firms have an advantage in transitioning economies? Toward a dynamic institution-based view. Strategic Management Journal, 36(9): 1358-1377.

Bennedsen, M., \& Foss, N. 2015. Family assets and liabilities in the innovation process. California Management Review, 58(1): 65-81.

Berrone, P., Cruz, C., \& Gomez-Mejia, L. R. 2012. Socioemotional wealth in family firms: Theoretical dimensions, assessment approaches, and agenda for future research. Family Business Review, 25(3): 258-279.

Bertrand, M., \& Schoar, A. 2006. The role of family in family firms. Journal of Economic Perspectives, 20(2): 73-96.

Beugelsdijk, S., Ambos, B., \& Nell, P.C. 2018. Conceptualizing and measuring distance in international business research: Recurring questions and practical recommendations. Journal of International Business Studies, forthcoming.

Bloom, N., \& Van Reenen, J. 2010. Why do management practices differ across firms and countries? The Journal of Economic Perspectives, 24(1): 203-224.

Byrne, D. E. 1971. The attraction paradigm (Vol. 11). New York:Academic Press.

Campbell, D. J., Bommer, W., \& Yeo, E. 1993. Perceptions of appropriate leadership style: Participation versus consultation across two cultures. Asia Pacific Journal of Management, 10(1): 1-19.

Carney, M., \& Gedajlovic, E. 2003. Strategic innovation and the administrative heritage of east Asian family business groups. Asia Pacific Journal of Management, 20(1): 5-26.

Chai, S. K., \& Rhee, M. 2010. Confucian capitalism and the paradox of closure and structural holes in east Asian firms. Management and Organization Review, 6(1): 5-29.

Chia, R., \& MacKay, B. 2007. Post-processual challenges for the emerging strategy-as-practice perspective: Discovering strategy in the logic of practice. Human Relations, 60(1): 217-242.

Chrisman, J. J., \& Patel, P. C. 2012. Variations in R\&D investments of family and nonfamily firms: Behavioral agency and myopic loss aversion perspectives. Academy of Management Journal, 55(4): 976-997.

Chua, J. H., Chrisman, J. J., \& Bergiel, E. B. 2009. An agency theoretic analysis of the professionalized family firm. Entrepreneurship Theory and Practice, 33(2): 355-372.

Claver, E., Rienda, L., \& Quer, D. 2009. Family firms' international commitment: The influence of familyrelated factors. Family Business Review, 22(2): 125-135.

D’Angelo, A., Majocchi, A., \& Buck, T. 2016. External managers, family ownership and the scope of SME internationalization. Journal of World Business, 51(4): 534-547.

Davis, J. H., Schoorman, F. D., \& Donaldson, L. 1997. Toward a stewardship theory of management. Academy of Management Review, 22(1): 20-47.

De Bary, W. T., Chan, W. T., \& Watson, B. 1960. Sources of Chinese tradition. New York:Columbia University Press.

De Massis, A., Di Minin, A., \& Frattini, F. 2015. Family-driven innovation: Resolving the paradox in family firms. California Management Review, 58(1): 5-19. 
De Massis, A., Wang, H., \& Chua, J.H. 2018. Counterpoint: How heterogeneity among family firms influences organizational change. Journal of Change Management, forthcoming. https://doi.org/10.1080 /14697017.2017.1419808.

Dyer, W. G. 2006. Examining the "family effect" on firm performance. Family Business Review, 19(4): $253-273$.

Fan, Y. 2000. A classification of Chinese culture. Cross Cultural Management: An International Journal, 7(2): 3-10.

Feather, N. T. 1988. Values, valences, and course enrolment: Testing the role of personal values within an expectancy value framework. Journal of Educational Psychology, 80: 381-391.

Fischer, R., \& Schwartz, S. 2011. Whence differences in value priorities? Individual, cultural, or artifactual sources. Journal of Cross-Cultural Psychology, 42(7): 1127-1144.

García-Álvarez, E., \& López-Sintas, J. 2001. A taxonomy of founders based on values: The root of family business heterogeneity. Family Business Review, 14(3): 209-230.

Ghemawat, P. 2001. Distance still matters. Harvard Business Review, 79(8): 137-147.

Gomez-Mejia, L. R., Haynes, K. T., Nunez-Nickel, M., Jacobson, K. J. L., \& Moyano-Fuentes, J. 2007. Socioemotional wealth and business risks in family-controlled firms: Evidence from Spanish olive oil mills. Administrative Science Quarterly, 52(1): 106-137.

Gomez-Mejia, L. R., Makri, M., \& Larraza-Kintana, M. L. 2010. Diversification decisions in familycontrolled firms. Journal of Management Studies, 47(2): 223-252.

Gupta, V., \& Levenburg, N. 2010. A thematic analysis of cultural variations in family businesses: The CASE project. Family Business Review, 23(2): 155-169.

Hall, A., Melin, L., \& Nordqvist, M. 2001. Entrepreneurship as radical change in the family business: Exploring the role of cultural patterns. Family Business Review, 14(3): 193-208.

Hitlin, S., \& Piliavin, J. A. 2004. Values: Reviving a dormant concept. Annual Review of Sociology, 30: 359-393.

Hofstede, G. 1980. Culture's consequences: International differences in work-related values. Beverly Hills:Sage.

Hofstede, G. 2007. Asian management in the 21st century. Asia Pacific Journal of Management, 24(4): 411-420.

Huntington, S. 1993. The clash of civilizations. Foreign Affairs, 72(3): 22-49.

Inglehart, R., \& Baker, W. E. 2000. Modernization, cultural change, and the persistence of traditional values. American Sociological Review, 65: 19-51.

Jennings, J. E., Dempsey, D., \& James, A. E. 2018. Bifurcated HR practices in family firms: Insights from the normative-adaptive approach to stepfamilies. Human Resource Management Review, 28(1): 68-82.

Jensen, M. C., \& Meckling, W. H. 1976. Theory of the firm: Managerial behavior, agency costs and ownership structure. Journal of Financial Economics, 3(4): 305-360.

Kano, L., \& Verbeke, A. 2018. Family firm internationalization: Heritage assets and the impact of bifurcation bias. Global Strategy Journal, forthcoming. https://doi.org/10.1002/gsj.1186.

Karam, C. M., Ralston, D. A., Egri, C. P., Butt, A., Srinivasan, N., Fu, P. P., \& Kuo, C. 2013. Perceptions of the ethicality of favors at work in Asia: An 11-society assessment. Asia Pacific Journal of Management, 30(2): 373-408.

Kelly, L. M., Athanassiou, N., \& Crittenden, W. F. 2000. Founder centrality and strategic behavior in the family-owned firm. Entrepreneurship Theory and Practice, 25(2): 27-42.

Kets de Vries, M. F. 1996. Family business: Human dilemmas in the family firm. Arden:International Thomson Business Press.

Kirby, W. C., \& Manty, T. Y. 2011. CP group: Balancing the needs of a family business with the needs of a family of businesses. Boston: Harvard Business School Publishing, Unit Case No. 312-059. Available at SSRN: https://ssrn.com/abstract=1998990.

Lee, K. S., Lim, G. H., \& Lim, W. S. 2003. Family business succession: Appropriation risk and choice of successor. Academy of Management Review, 29(4): 657-666.

Lubatkin, M. H., Schulze, W. S., Ling, Y., \& Dino, R. N. 2005. The effects of parental altruism on the governance of family-managed firms. Journal of Organizational Behavior, 26(3): 313-330.

Luo, Y. 2008. The changing Chinese culture and business behavior: The perspective of intertwinement between guanxi and corruption. International Business Review, 17(2): 188-193.

Majocchi, A., \& Strange, R. 2012. International Diversification: The Impact of Ownership Structure, the Market for Corporate Control and Board Independence. Management International Review, 52(6): 879900.

Majocchi, A., D’Angelo, A., Forlani, E., \& Buck, T. 2018. Bifurcation bias and exporting: Can foreign work experience be an answer? Insight from European family SMEs. Journal of World Business, 53(2): 237-247.

Miller, D., Le Breton-Miller, I., \& Scholnick, B. 2008. Stewardship vs. stagnation: An empirical comparison of small family and non-family businesses. Journal of Management Studies, 45(1): 51-78.

Miller, D., Wright, M., Breton-Miller, I. L., \& Scholes, L. 2015. Resources and innovation in family businesses: The Janus-face of socioemotional preferences. California Management Review, 58(1): 20-40. 
Nordqvist, M. 2005. Understanding the role of ownership in strategizing: A study of family firms. $\mathrm{PhD}$ dissertation, Jönköping International Business School, Jönköping, Sweden.

Oh, C. H., \& Rugman, A. M. 2007. Regional multinationals and the Korean cosmetics industry. Asia Pacific Journal of Management, 24(1): 27-42.

Pandit, D., \& Sahay, A. 2013. Nurturing green: The growth dilemma (C). London:Ivey Publishing.

Patel, P. C., \& Chrisman, J. J. 2014. Risk abatement as a strategy for R\&D investments in family firms. Strategic Management Journal, 35(4): 617-627.

Pratt, D. D. 1991. Conceptions of self within China and the United States: Contrasting foundations for adult education. International Journal of Intercultural Relations, 15(3): 285-310.

Rugman, A. M., \& Verbeke, A. 2004. A perspective on regional and global strategies of multinational enterprises. Journal of International Business Studies, 35(1): 3-18.

Sagiv, L., \& Schwartz, S. H. 2007. Cultural values in organisations: Insights for Europe. European Journal of International Management, 1(3): 176-190.

Schwartz, S. H. 1992. Universals in the content and structure of values: Theoretical advances and empirical tests in 20 countries. Advances in Experimental Social Psychology, 25: 1-65. New York: Academic Press.

Schwartz, S. H. 1996. Value priorities and behavior: Applying a theory of integrated value systems. In C. Seligman, J. M. Olson \& M. P. Zanna (Eds.), The psychology of values: Vol. 8 The Ontario symposium: 1-24. Hillsdale, NJ: Erlbaum.

Schwartz, S. H. 1999. A theory of cultural values and some implications for work. Applied Psychology, 48(1): 23-47.

Schwartz, S. H. 2006. A theory of cultural value orientations: Explication and applications. Comparative Sociology, 5(2): 137-182.

Schwartz, S. H. 2010. Values: Individual and cultural. In S. M. Breugelmans, A. Chasiotis, \& F. J. R. van de Vijver (Eds.). Fundamental questions in cross-cultural psychology: 463-493. Cambridge: Cambridge University Press.

Schwartz, S. H. 2011. Studying values: Personal adventure. future directions. Journal of Cross-Cultural Psychology, 42(2): 307-319.

Schwartz, S. H., \& Bardi, A. 2001. Value hierarchies across cultures: Taking a similarities perspective. Journal of Cross-Cultural Psychology, 32(3): 268-290.

Schwartz, S. H., Cieciuch, J., Vecchione, M., Davidov, E., Fischer, R., Beierlein, C., Ramos, A., et al. 2012. Refining the theory of basic individual values. Journal of Personality and Social Psychology, 103(4): 663.

Schwartz, S. H., \& Rubel, T. 2005. Sex differences in value priorities: Cross-cultural and multimethod studies. Journal of Personality and Social Psychology, 89(6): 1010-1028.

Sciasca, S., Mazzola, P., Astrachan, J., \& Pieper, T. 2013. Family involvement in the board of directors: Effects on sales internationalization. Journal of Small Business Management, 51(1): 83-99.

Sharma, P., \& Chua, J. H. 2013. Asian family enterprises and family business research. Asia Pacific Journal of Management, 30(3): 641-656.

Steier, L. P. 2009. Familial capitalism in global institutional contexts: Implications for corporate governance and entrepreneurship in East Asia. Asia Pacific Journal of Management, 26(3): 513-535.

Tan, R. S. K., \& Wiwattanakantang, Y. 2016. Cargill: Keeping the family business private. London: Ivey Publishing.

Tan, W. L., \& Fock, S. T. 2001. Coping with growth transitions: The case of Chinese family businesses in Singapore. Family Business Review, 14(2): 123-139.

Thaler, R. H., \& Shefrin, H. M. 1981. An economic theory of self-control. Journal of Political Economy, 89(2): 392-406.

Thams, Y., Liu, Y., \& Von Glinow, M. A. 2013. Asian favors: More than a cookie cutter approach. Asia Pacific Journal of Management, 30(2): 461-486.

Thomas, D. C., Au, K., \& Ravlin, E. C. 2003. Cultural variation and the psychological contract. Journal of Organizational Behavior, 24(SI: Employment Relationships): 451-471.

Vallejo, M. C. 2009. The effects of commitment of non-family employees of family firms from the perspective of stewardship theory. Journal of Business Ethics, 87(3): 379-390.

Verbeke, A. 2013. International business strategy. Cambridge:Cambridge University Press.

Verbeke, A., \& Kano, L. 2012. The transaction cost economics theory of the family firm: Family-based human asset specificity and the bifurcation bias. Entrepreneurship Theory and Practice, 36(6): 1183-1205.

Verbeke, A., \& Kano, L. 2013. The transaction cost economics (TCE) theory of trading favors. Asia Pacific Journal of Management, 30(2): 409-431.

Williams, R. I., Pieper, T. M., Kellermanns, F. W., \& Astrachan, J. H. 2018. Family firm goals and their effects on strategy, family and organization behavior: A review and research agenda. International Journal of Management Reviews, 20: S63-S82. 
Yan, J., \& Sorenson, R. 2006. The effect of Confucian values on succession in family business. Family Business Review, 19(3): 235-250.

Yang, M. M. H. 2002. The resilience of guanxi and its new deployments: A critique of some new guanxi scholarship. The China Quarterly, 170: 459-476.

Yuan, W., \& Wu, Z. 2018. A value perspective of family firms. Entrepreneurship Theory and Practice, forthcoming. https://doi.org/10.1177/1042258717748934.

Zahra, S. A. 2003. International expansion of US manufacturing family businesses: The effect of ownership and involvement. Journal of Business Venturing, 18(4): 495-512.

Zahra, S. A., Hayton, J. C., Neubaum, D. O., Dibrell, C., \& Craig, J. 2008. Culture of family commitment and strategic flexibility: The moderating effect of stewardship. Entrepreneurship Theory and Practice, 32(6): $1035-1054$.

Zellweger, T. M., Kellermanns, F. W., Chrisman, J. J., \& Chua, J. H. 2012. Family control and family firm valuation by family CEOs: The importance of intentions for transgenerational control. Organization Science, 23(3): 851-868.

Publisher's note Springer Nature remains neutral with regard to jurisdictional claims in published maps and institutional affiliations.

Dr. Alain Verbeke is a Professor of International Business Strategy and holds the McCaig Research Chair in Management at the Haskayne School of Business, University of Calgary. He is also the Research Director of the Strategy and Organization Area at the Haskayne School of Business. In 2014, Dr. Verbeke was elected as the Inaugural Alan M. Rugman Memorial Fellow at the Henley Business School, University of Reading (UK). $\mathrm{He}$ is the Editor-in-Chief of the Journal of International Business Studies (2017 - 2019).

Dr. Wenlong Yuan is the Stu Clark Chair in entrepreneurship and innovation at the Asper School of Business, the University of Manitoba, Canada. His main research interests cross entrepreneurship, strategy, and international business. His work currently focuses on entrepreneurship in large firms, the impact of top management teams' characteristics on middle-level entrepreneurial activities, entrepreneurial learning from failure, and behaviors of academic entrepreneurs.

Liena Kano is an Associate Professor of Strategy and Global Management at the Haskayne School of Business, University of Calgary, Canada. Her research interests lie at the intersection of strategic management, international business and entrepreneurship, with a particular focus on novel applications of internalization theory, and on microfoundations that underlie complex international governance decisions. 